\title{
Hydrodynamics around an Artificial Surfing Reef at Leirosa, Portugal
}

\author{
Ana Mendonça, M.Sc. ${ }^{1}$; Conceição Juana Fortes, Ph.D. ${ }^{2}$; Rui Capitão, Ph.D. ${ }^{3}$; Maria Graça Neves, Ph.D. \\ José Simão Antunes do Carmo, Ph.D. ${ }^{5}$; and Theo Moura, M.Sc. ${ }^{6}$
}

\begin{abstract}
As a new alternative countermeasure to protect the coastal zone and to increase the surfing possibilities in the Leirosa area of Portugal, multifunctional artificial reefs were investigated numerically in this paper. The primary surfing parameters used in the design (i.e., breaker type, peel angle, wave height at breaking, and currents around the artificial reef) were analyzed. The reef functionality was also analyzed for coastal protection. Two reef geometries with different reef angles of 45 and $66^{\circ}$ were tested, considering two design wave conditions (storm and common) and two tide levels (medium and low). Simulations show that both reef geometries are adequate for surfing, although the reef angle of $66^{\circ}$ is more suitable for standard surfers, and the $45^{\circ}$ angle is more adequate for advanced/professional surfers. A morphodynamic study should be carried out to analyze the efficiency of the artificial surf reef for coastal protection. DOI: 10.1061/ (ASCE)WW.1943-5460.0000128. (C) 2012 American Society of Civil Engineers.
\end{abstract}

CE Database subject headings: Coastal environment; Reefs; Hydrodynamics; Parameters; Numerical models; Portugal; Case studies.

Author keywords: Surfing; Coastal protection; Multifunctional artificial reefs; Reef parameters; Numerical modeling.

\section{Introduction}

The economic importance of coastal zones has been growing in the past few decades, and a growing numbers of visitors wanting to enjoy a sandy beach on holidays and to practice outdoor sports, such as surfing, sailing, and fishing, are imposing great pressure on these areas.

Many coastal zones are now suffering from erosion, and the aspects and characteristics that make the coasts so attractive could be among the causes of their gradual destruction.

In Portugal, there are several examples of coastline erosion and degradation. Common problems are the erosion of the dune system as a result of a single storm event, which may lead to flooding of the hinterland, as illustrated in the case of Vagueira (Gomes and Pinto

${ }^{1} \mathrm{Ph} . D$. Student, Laboratório Nacional de Engenharia Civil, Departamento de Hidráulica e Ambiente, Av. do Brasil 101, 1700-066 Lisboa, Portugal. E-mail: amendonca@lnec.pt

${ }^{2}$ Senior Research Officer, Laboratório Nacional de Engenharia Civil, Departamento de Hidráulica e Ambiente, Av. do Brasil 101, 1700-066 Lisboa, Portugal. E-mail: jfortes@lnec.pt

${ }^{3}$ Research Officer, Laboratório Nacional de Engenharia Civil, Departamento de Hidráulica e Ambiente, Av. do Brasil 101, 1700-066 Lisboa, Portugal. E-mail: rcapitao@lnec.pt

${ }^{4}$ Research Officer, Laboratório Nacional de Engenharia Civil, Departamento de Hidráulica e Ambiente, Av. do Brasil 101, 1700-066 Lisboa, Portugal. E-mail: gneves@lnec.pt

${ }^{5}$ Associate Professor, IMAR/FCTUC, Departamento de Engenharia Civil, 3030-788 Coimbra, Portugal (corresponding author). E-mail: jsacarmo@dec.uc.pt

${ }^{6}$ Research Trainee, Laboratório Nacional de Engenharia Civil, Departamento de Hidráulica e Ambiente, Av. do Brasil 101, 1700-066 Lisboa, Portugal. E-mail: tmoura@lnec.pt

Note. This manuscript was submitted on June 10, 2010; approved on September 20, 2011; published online on September 22, 2011. Discussion period open until October 1, 2012; separate discussions must be submitted for individual papers. This paper is part of the Journal of Waterway, Port, Coastal, and Ocean Engineering, Vol. 138, No. 3, May 1, 2012. (C)ASCE, ISSN 0733-950X/2012/3-226-235/\$25.00.
2006), and the collapse of properties located on cliff tops and dunes, as documented in Vale do Lobo and Estela, Portugal (European Commission 2004; Gomes and Pinto 2006).

Multifunctional artificial reefs (MFARs) are an innovative concept for coastal protection. Current understanding of the functional design of these structures may be insufficient for optimum design, but it may be good enough for these structures to be considered serious alternatives for coastal protection (Pilarczyk 2003). The implementation of MFARs (coastal protection and increasing the surfing possibilities in a certain area) are explained in greater detail elsewhere (Beamsley and Black 2003; Hiliau and Phillips 2003; Jackson et al. 2004; Ranasinghe et al. 2006; Voorde et al. 2008; Voorde et al. 2009).

The construction of an MFAR can play a part in coastal protection by:

- Preventing coastal erosion; and

- Increasing, in combination or not with sand nourishment, the stability of beaches.

These two sorts of coastal protection are possible because an MFAR can:

- Reduce the wave loads on the coast through a series of wave transformation processes occurring on the structure, viz, reflection and energy dissipation owing to waves breaking on the structure and to flow circulation inside the porous media;

- Create current circulation cells behind the reef, which can cause sedimentation at the shoreline; and

- Be used to regulate wave action by refraction and diffraction. One kind of design causes waves to break over an MFAR in such a way that surfers can enjoy great sport riding them. Surfing and bodyboarding are growing in popularity and are especially practiced by young people.

The Leirosa sand dune system is one example of a system in which strong erosion can be observed. To stop a regression of approximately $4-5 \mathrm{~m}$ each year, especially after 2000 , a rehabilitation program of the Leirosa sand dune system using geotextile sand containers (geocontainers) was implemented (Antunes do Carmo et al. 2010). More recently, to turn this area into an attractive and safe 
coastal dune system, an MFAR has been studied to see if it would contribute to stabilize the existing geotextile-reinforced sand dune system and contribute to the enhancement of the surfing conditions.

This paper presents an analysis of the performance of the MFAR at Leirosa for surfability. The incident wave conditions were defined on the basis of the local wave regime at Leirosa beach and on the findings of Voorde et al. (2008). The reef's geometry and location are assessed using the theoretical study of Voorde (2009).

The analysis of the surfability used numerical simulations with the Cornell University Long and Intermediate Wave Modeling Package (COULWAVE) (Lynett and Liu 2004). The breaker type, the peel angle, and the wave height around the artificial reef were analyzed. The mean current field was also observed.

\section{General Background and Wave Regimes}

\section{Zone Characterization}

The study area considered in this paper is located in Leirosa, to the south of Figueira da Foz, midway along the West Atlantic coast of Portugal (Fig. 1). This coastal stretch is characterized by strong erosion primarily resulting from littoral drift retention caused by the Figueira da Foz port and reduced sediment deposition caused by the interventions carried out in the Mondego River (Duarte and Reis 1992). The construction of groynes made to protect several urban populations, including Leirosa, caused the retention of large amounts of sand to the north of the study area and a natural increase of erosion to the south.

\section{Local Wave Regimes}

The local wave regime at Leirosa was determined from available recorded wave data collected at a buoy located near Figueira da Foz on the $-25 \mathrm{~m}(\mathrm{CD})$ water depth contour, with coordinates $40^{\circ} 03^{\prime}$ $22^{\prime \prime} \mathrm{N} ; 8^{\circ} 57^{\prime} 22^{\prime \prime} \mathrm{W}$ (P5). The primary wave parameters significant wave height (HS), average wave period (TZ), and wave direction (DIR) were obtained from those wave records for a 7-month period, from October 2008 to May 2009 (Costa 2009). Fig. 2 shows contour plots HS versus TZ, HS versus DIR, and TZ versus DIR of the number of occurrences obtained for each pair of classes at that location, using the mentioned wave data set.

From Fig. 2, it is possible to conclude that:

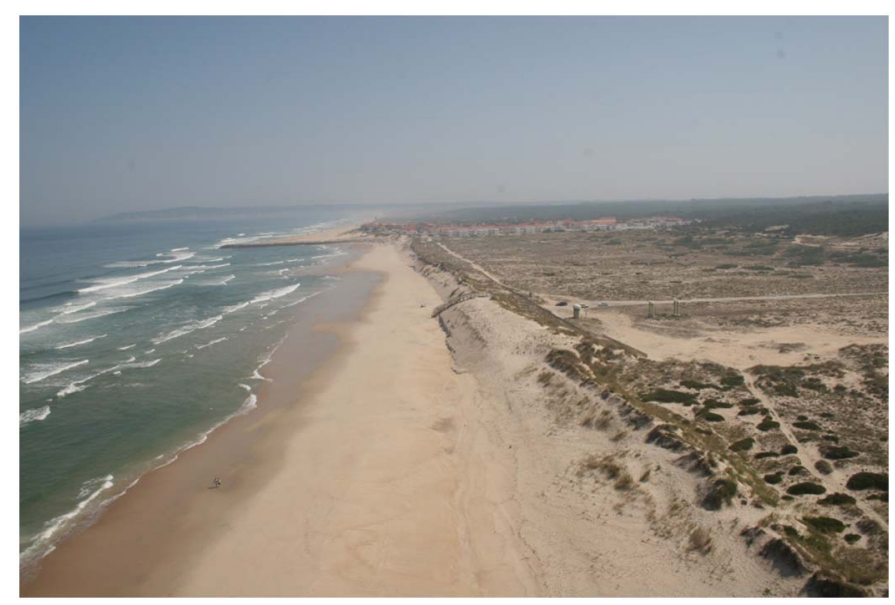

Fig. 1. Leirosa beach and dune system under study (image by the authors)
- The most frequent directions at P5 occur in the $275-325^{\circ}$ range, whereas most occurrences are found in the $295-310^{\circ}$ range. These are generally associated with significant wave heights HS less than $3.0 \mathrm{~m}$ and mean periods TZ of 5-9 s.

- The HS values are less than $8.5 \mathrm{~m}$, and most occurrences are found in the[1.0-1.5 and 1.5-2.0 m classes.

- The TZ values vary 4-12 s, with the most frequent between 5-10 s.

\section{Wave Conditions}

On the basis of the local wave regime, the design waves considered in the study of Voorde et al. (2008) included two distinct wave conditions (with wave height $H$ and wave period $T$ ). The same wave conditions are simulated in this paper for two reef geometries with different reef angles. The two design wave conditions are:

- For typical storm conditions on the Portuguese west coast: $H=4.0 \mathrm{~m}, T=15 \mathrm{~s}$; and

- For common conditions on the Portuguese west coast: $H=1.5 \mathrm{~m}, T=9 \mathrm{~s}$.

A case without reef is also considered for a wave condition of $H=1.5 \mathrm{~m}$ and $T=8 \mathrm{~s}$.

These simulations took into account that the reef will be designed with two goals in mind: to increase the local surfing possibilities and to promote better coastal protection.

The incident angle of the waves is chosen to be $0^{\circ}$, because the point of the crest will be directed toward the most common wave directions, giving the best surfing conditions as derived by Voorde et al. (2008). The direction angle is given as an angle in degrees measured clockwise starting from the North direction $\left(0^{\circ}\right)$. A mean tide water level (MWL) of $2.0 \mathrm{~m}(\mathrm{CD})$ and a low tide water level (LWL) of $1.0 \mathrm{~m}(\mathrm{CD})$ were considered for the second (common) design condition, whereas only the MWL was considered for the first (storm) design condition.

\section{Hydrodynamics around a Multifunctional Artificial Reef}

The efficiency of an MFAR is related to its functionality with respect to both surfability (i.e., the possibility to surf a wave) and coastal protection. For surfability, a numerical study has been conducted to define the most appropriate geometry for the MFAR. Before that, the following remarks about surfability parameters can be drawn.

\section{Reef Functionality and Design Parameters: Surfability Parameters}

An important purpose of an MFAR is the creation of local surfing conditions. Following are detailed the key surfing parameters used to design the MFAR, which are the breaker type, the peel angle, the surfing maneuvers, the configuration of wave sections, the wave height at breaking, and the currents.

\section{Breaker Type}

The shape of a breaking wave is of great importance for surfing. Battjes (1974) used the Iribarren number $\xi_{b}$ [Eq. (1)], to describe the breaker type on single slopes

$$
\xi_{b}=\frac{s}{\sqrt{\frac{H_{b}}{L_{o}}}}
$$

where $\xi_{b}=$ inshore Iribarren number; $s=$ bottom slope; $H_{b}=$ wave height at breaking; and $L_{o}=$ deep water wave length.

For a preliminary analysis of the conditions required for breaking, the Iribarren number $\xi_{b}$ is used, with greater values indicating more-intense breaking. This parameter provides an indication that 

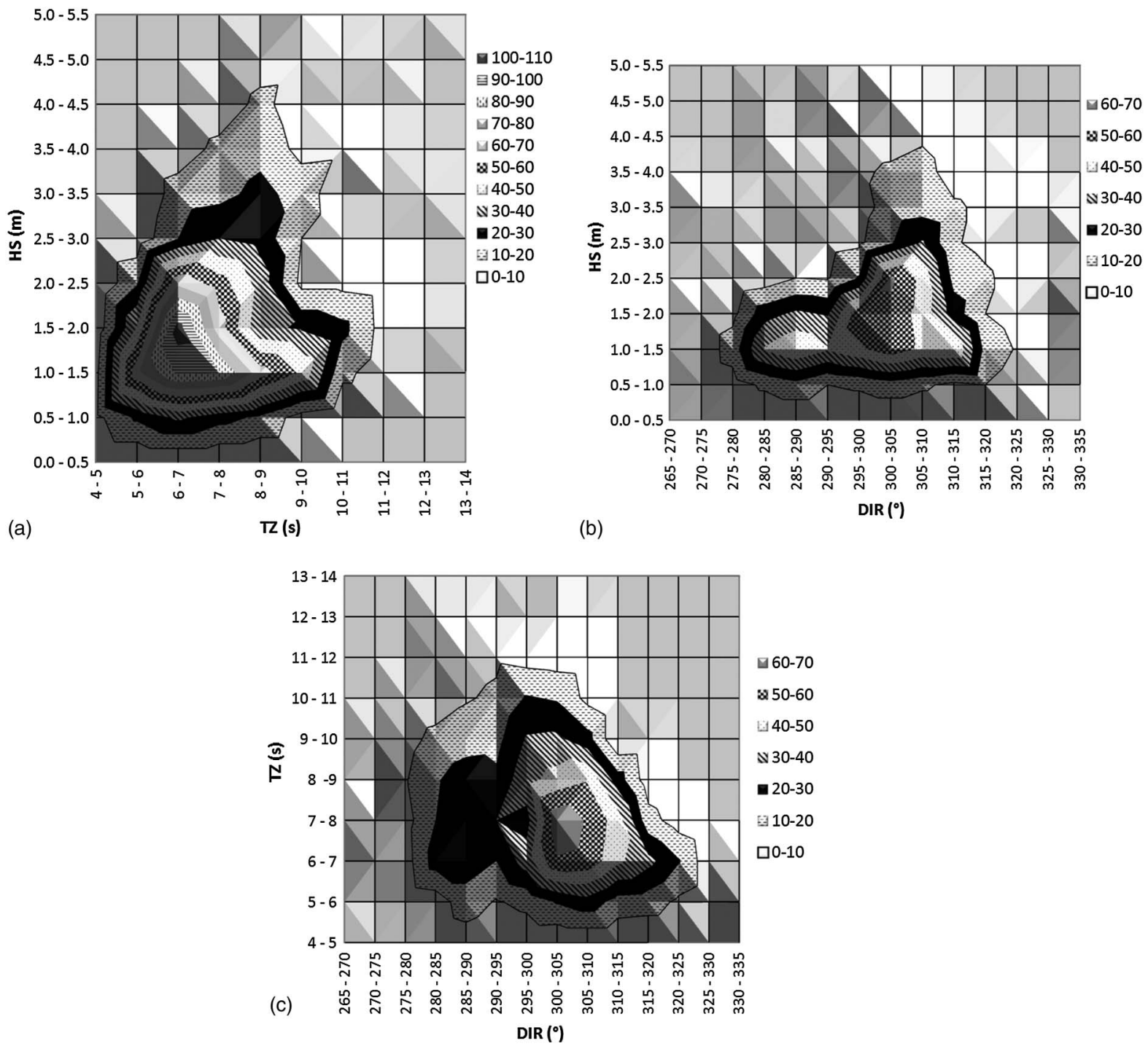

Fig. 2. Local wave characterization; contour plots of the number of occurrences at P5: (a) HS versus TZ; (b) HS versus DIR; (c) TZ versus DIR

the breaker shape varies between spilling $\left(\xi_{b}<0.4\right)$, plunging $\left(0.4<\xi_{b}<2\right)$, and surging/collapsing $\left(\xi_{b}>2\right)$ types. As defined by Dally (2001), surf zone conditions for which $\xi_{b}<0.3$ are considered unsuitable for surfing. The primary breaking types, described by Galvin (1968) and Battjes (1974), have the following interpretation from Henriquez (2004): spilling breakers are considered surfable; plunging breakers are preferred by most surfers, with spilling plunging waves preferred over collapsing plunging waves; and finally, collapsing and surging breakers are considered unsurfable.

The use of the Iribarren number to predict breaking waves for surfing is questionable, but it is the most appropriate method.

\section{Peel Angle}

The peel angle, related to the break angle and the wave obliquity at the broken depth, determines the speed that the surfer must adopt to stay ahead of the breaking section of the wave. The peel angle $\alpha$ is the angle enclosed by the wave crest and the breaker line (Walker 1974), or the angle enclosed by the velocity vectors of the peel rate $\vec{V}_{p}$ and the downline velocity $\vec{V}_{S}$ (Henriquez 2004), as shown in Fig. 3.

$$
\vec{V}_{S}=\frac{\vec{c}}{\sin \alpha}
$$

where $\vec{c}=$ wave celerity.

Peel angles vary from $0-90^{\circ}$ with zero peel angles corresponding to what is referred to as a "close out," where the waves break simultaneously along the entire crest. As peel angles increase the speed of breaking along the crest, which approximates the surfer velocity, slows to a speed suitable for experienced surfers. This occurs for peel angles of approximately $30-45^{\circ}$, with the optimal peel angle for most recreational surfers considered to be in the range of $45-66^{\circ}$.

A minimum peel angle of $30^{\circ}$ is generally required for surfing (Walker 1974). Large peel angles are generally associated with nonuniform bottom contours (e.g., wave breaking on the edge of a bar/reef). A wave with a very large peel angle is considered too slow for good surfing. The velocity that a surfer can reach depends primarily on the wave height $H_{b}$ found at the breaking point and obviously on the surfer skills. Hutt et al. (2001) investigated what the peel angle $\alpha$ was for given wave heights $H_{b}$ and surfer skills. The definitions of surfer skill ratings are shown in Table 1. 


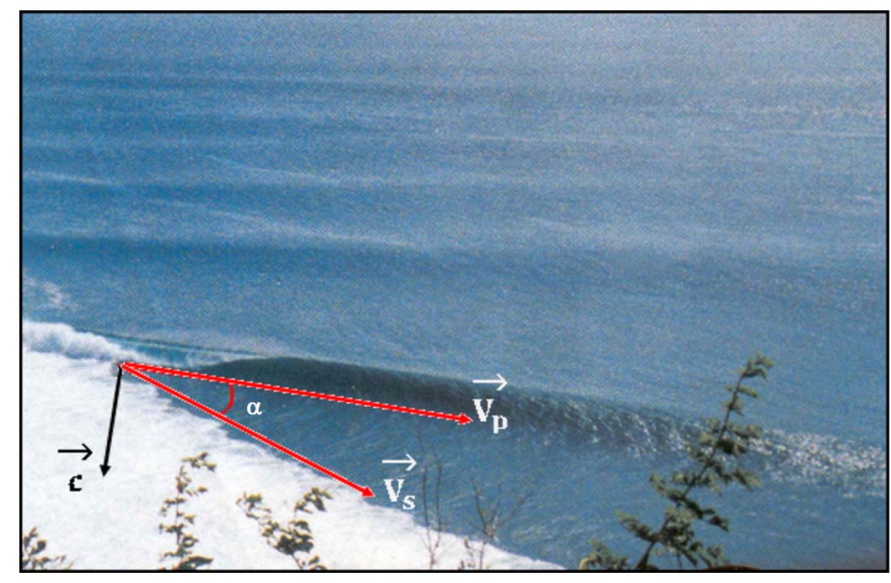

Fig. 3. Illustration of wave celerity vector, peel rate, downline velocity, and peel angle $\alpha$ (image by the authors)

Henriquez et al. (2006) proved algebraically that, for an arbitrary peel angle, wave height, and offshore depth (in the context of a geometrical optics approximation of linear wave theory), the maximum peel angle occurs at an angle of $66^{\circ}$ in deep water conditions. This algebraic proof means that regardless of wave conditions and offshore depth, an angle of $66^{\circ}$ in deep water conditions is always found to be the maximum peel angle.

Studies have related surfers to surfing waves to determine design criteria for artificial surfing reefs. This research falls into two categories. The first relates a surfer's skill level to surfing wave parameters. The second relates surfing maneuvers to surfing wave parameters (Scarfe et al. 2003).

Different surfing waves suit different types of surfers, and surfers prefer to ride waves that match or challenge their abilities. The range of wave heights, peel angles, breaking intensities, and section lengths that a surfer can successfully negotiate depends on the surfer's skill level (Scarfe et al. 2003).

The more surfing skill required, the greater the ability to negotiate difficult sections and link sections together for long surfing rides. Moores (2001) looked at how skill level related to a surfer's ability to surf through wave sections with decreases in peel angles. The general findings were:

- The more skill, the longer the sections that can be made;

- Surfers with advanced skill levels do not require as much speed when coming into a section because they have more ability to generate speed; and

- Surfers with a beginner skill level cannot make sections.

\section{Surfing Maneuvers}

Surfing is a recreational activity, and performing maneuvers is the goal of most surfers. The types of maneuvers a surfer performs are dependent on ability, style of surfing, and type of waves. For any given type of waves, most surfers will perform similar types of maneuvers (Scarfe 2002; Scarfe et al. 2002). According to Scarfe (2002), each maneuver can be categorized as functional, transitional, or expressive, depending on when it is being done. Functional maneuvers are required for anyone to surf. A functional maneuver, such as speed weaving, is required simply to keep up with a breaking wave. A functional maneuver performs the function of staying in the powerful section of the wave. Maneuvers such as top turns and bottom turns can be considered transitional moves that are used to link together functional maneuvers with expressive maneuvers. A bottom turn may be functional when dropping into a wave, transitional when preparing for an aerial, or expressive when executed under certain conditions.

Analysis of peel angles during certain maneuvers by Scarfe (2002) and presented in Scarfe et al. (2002) yielded design criteria to incorporate a maneuver type into wave sections of artificial surfing reefs (Fig. 4. Scarfe (2002) described the surfing maneuvers as takeoff, cutback, reo, and speed section. These maneuvers represent the division in peel angles at which a maneuver can be performed. For example, although the word "cutback" is used, in the analysis it is just as likely that a surfer will perform a roundhouse for the given wave scenario. When surfing through a speed section, a surfer can speed weave, perform a floater or foam bounce, or experience a barrel ride if the breaker intensity is great enough (Scarfe et al. 2003).

Henriquez (2004) performed experiments to estimate the typical paddling speed in still water. Three types of paddling are primarily distinguished from each other by the duration a surfer can maintain

Table 1. Rating of Surfer Skill Level (Adapted from Hutt et al. 2001)

\begin{tabular}{|c|c|c|c|}
\hline Rating & Description & Peel angle $\alpha\left({ }^{\circ}\right)$ & $H_{b}$ minimum-maxium $(\mathrm{m})$ \\
\hline 1 & $\begin{array}{l}\text { Beginner surfers not yet able to ride the face of a wave } \\
\text { who simply move forward as the wave advances }\end{array}$ & 90 & $0.70-1.00$ \\
\hline 2 & $\begin{array}{l}\text { Learner surfers able to successfully ride laterally along } \\
\text { the crest of a wave }\end{array}$ & 70 & $0.65-1.50$ \\
\hline 3 & $\begin{array}{l}\text { Surfers who have developed the skill to generate speed by } \\
\text { "pumping" on the face of the wave }\end{array}$ & 60 & $0.60-2.50$ \\
\hline 4 & $\begin{array}{l}\text { Surfers beginning to initiate and execute standard surfing } \\
\text { maneuvers on occasion }\end{array}$ & 55 & $0.55-4.00$ \\
\hline 5 & $\begin{array}{l}\text { Surfers able to execute standard maneuvers consecutively } \\
\text { on a single wave }\end{array}$ & 50 & $0.50-4.00+$ \\
\hline 6 & $\begin{array}{l}\text { Surfers able to execute standard maneuvers consecutively } \\
\text { and execute advanced maneuvers on occasion }\end{array}$ & 40 & $0.45-4.00+$ \\
\hline 7 & $\begin{array}{l}\text { Top amateur surfers able to consecutively execute } \\
\text { advanced maneuvers }\end{array}$ & 29 & $0.40-4.00+$ \\
\hline 8 & $\begin{array}{l}\text { Professional surfers able to consecutively execute } \\
\text { advanced maneuvers }\end{array}$ & 27 & $0.35-4.00+$ \\
\hline
\end{tabular}




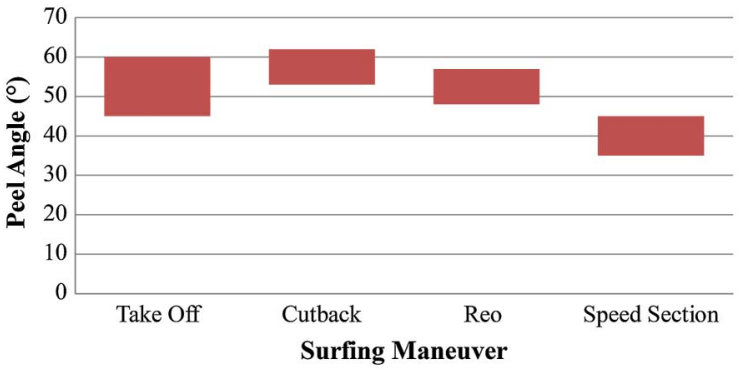

Fig. 4. Range of peel angles suitable for different surfing maneuvers (adapted from Scarfe 2002; Scarfe et al. 2002)

the paddling speed. Slow paddling can be maintained for more than 10 min, moderate paddling can be maintained for only a few minutes, and fast paddling, which is specifically used to support the take off, can be maintained for only a few seconds (Van Ettinger 2005).

\section{Configuration of Wave Sections}

Variation in any of the four surfing wave parameters creates a new section. Different maneuvers can be performed depending on the configuration of wave sections. Incorporating interesting and varying sections into artificial surfing reefs will challenge surfers and keep rides interesting. Maneuver type for a section is also dependent on the previous section (Scarfe et al. 2002). For example, a surfer riding a section with a low peel angle will be traveling fast to keep up with the wave break point. If the next section dramatically increases in peel angle, then the surfer will perform a move such as a cutback to lose speed and stay in the powerful pocket of the wave.

Although peel angles can be too large to challenge more advanced surfers, large peel angles do not necessarily prevent surfers from riding waves, whereas low peel angles do (Scarfe et al. 2003).

\section{Wave Height}

Surfers who use a long board are still surfing when waves are 0.15 $\mathrm{m}$ high, whereas those who are towed into waves ride the biggest waves they can find, up to $20 \mathrm{~m}$. On the whole, waves between 0.5-10 m are considered surfable (Henriquez 2004). To study the viability of an MFAR, wave heights of 1-3 $\mathrm{m}$ are normally used and are adjusted according to the target level of surfers for which the MFAR is being designed.

\section{Currents}

Currents around an MFAR are of vital importance for the surfability of the breaking waves. Rip currents, narrow strong currents that move seaward through the surf zone (Shepard and Inman 1950; Bowen 1969; MacMahan et al. 2006), can negatively affect the wave surfability. Henriquez (2004) observed in an experimental laboratory model that approximately $20 \%$ of the wave ride was negatively affected by the rip currents driven by the wave breaking over the MFAR. Observations showed that the rip current tended to induce the breaking of the incoming waves, making the waves unsuitable for surfing.

Another possibility is that the waves are perfectly surfable but unreachable because of strong currents. However, rip currents can also be advantageous: the surfer can use them to get outside the breaker zone easily and return to the take off zone, the area in which surfers start the wave ride (Henriquez 2004).

When a current flows seaward through the breaker zone, the waves increase in height, causing them to break earlier. This moves the breaker line offshore and may result in peel angles potentially too low to be suitable for surfing (Van Ettinger 2005).

Henriquez (2004) observed in an experiment that waves in a rip current break irregularly and in sections. This may be caused by variations in the velocity of the rip current, which results, according to the dispersion relationship used by Van Ettinger (2005), in variations in wave heights. These variations in wave heights can be the cause of the irregularly and sectional breaking of the waves.

The primary driving mechanisms for the rip currents through the breakers caused by the artificial reef are the currents induced by differences in pressure gradients. These pressure gradients occur owing to differences in breaker heights over the reef and at the sides of the reef. The rip currents are also driven by the alongshore current along the reef (Van Ettinger 2005). In the design of artificial surfing reefs, the surfability of the break owing to wave-driven currents must be considered if the amenity is to be maximized, especially during large surf conditions.

The surfability of the reef could be enhanced, as pointed out by Phillips et al. (2003) for the study of Narrowneck surfing reef on the Gold Coast, Australia, by the incorporation of a paddling channel, especially during large swell conditions, when access to the take off point could prove difficult. Even though wave-driven currents are directed inshore on the outer sides of the reef, the current is reversed through the paddling channel, aiding paddling out through the channel. In addition, shoreward of the reef, a quiet zone should provide sheltered paddling from the beach.

Cáceres et al. (2010), through detailed laboratory experiments, examined three artificial surfing reef layouts that differ in the alongshore separation distance between two symmetrical reef sides, with the purpose to mitigate the negative effects of wave-breakinginduced currents on the surfability. The study shows that increasing the separation distance leads to a significant reduction of the obliquely exiting rip currents at the outer sides of the reef but an increase in the flow circulation onshore of the gap. This has a positive effect on the surfability by reducing the negative effects associated with the wave-current interaction on the wave breaking, thus providing longer rides.

\section{Reef Parameters and Local Bathymetry}

The design of an artificial reef built to both protect the local coastline and to create surfing conditions has to consider several design parameters. This study, which uses Voorde et al. (2008) methodology, concentrates on the hydrodynamics, but once an optimal geometry concerning the hydrodynamics is determined, a thorough morphodynamic study (physical and/or numerical) is necessary to investigate the capacity of an MFAR to protect a local coastline.

The parameters defined for an optimal geometry were the reef angle, the height of the reef, the submergence of the reef, the geometry of the reef, its horizontal dimensions, and the side slope of the reef (Fig. 5). A delta-shaped geometry comprising two rides (a left and a right ride) was chosen. According to the theoretical study of Voorde et al. (2009), two constant MFAR angles of 45 and $66^{\circ}$ were tested.

Voorde et al. (2009a) tested several wave conditions (common and storm wave conditions) to define the optimal geometry of the MFAR for surfability. Regarding the breaker line for the storm wave conditions, a reef angle of $45^{\circ}$ is better because it produces longer breaker lines, enabling surfers to make a longer ride. Concerning the peel angle, both for the storm wave and for common wave conditions, a reef angle of $66^{\circ}$ is the best choice for amateur surfers. 


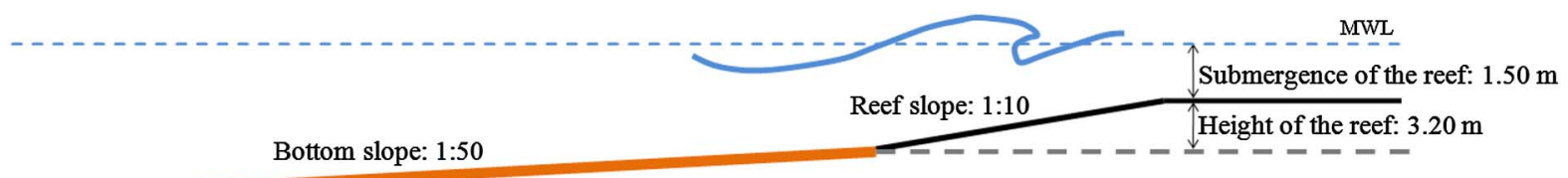

Fig. 5. Schematic representation of geometry tested

Concerning the wave height at the breaker point, the preferred wave height depends on the skill of the surfer. The greater the skill of the surfer, the higher the wave preferred. However, it is easier to start surfing for every surfer when the wave is somewhat higher at the beginning, especially when the peel angle is small.

Plunging waves with an inshore Iribarren number ranging from 0.6-0.9 are the best to surf for both amateur and professional surfers (Henriquez 2004). To catch the wave in the beginning, an Iribarren number value of approximately 0.6 at the beginning of the ride is preferred.

The submergence of the reef is determined by two factors. First, it should be shallow enough for the design waves to break on the reef. Second, it should be deep enough to ensure the safety of surfers.

For the common wave conditions tested, the design wave height of $1.50 \mathrm{~m}$ gives a good surfable plunging wave for a submergence of $1.50 \mathrm{~m}$. The height of the reef is defined to be approximately $3.20 \mathrm{~m}$, with a seaward slope of $1: 10$ and a bottom slope of 1:50 (Figs. 5 and 6). As stated, two different reef angles (45 and $66^{\circ}$ ) were tested (Fig. 6).

The reef profile shape shown in Fig. 5 was considered in this study; however, an effort should be done to keep the breaking intensity fairly constant over the entire range of design wave heights. According to Hearin (2006) for the Cocoa beach reef, this is achieved by designing a reef with a convex profile shape (gradients varying from 1:5 at the toe to $1: 20$ at the crest).

The breaker type characterization follows the methodology proposed by Battjes (1974) for a plane beach. In the work developed by Neves et al. (2010), two-dimensional (2D) physical model tests were performed to investigate the relationship between the breaker type, the submergence, and the length of an MFAR composed of geotextile sand containers. The primary conclusion is that for both

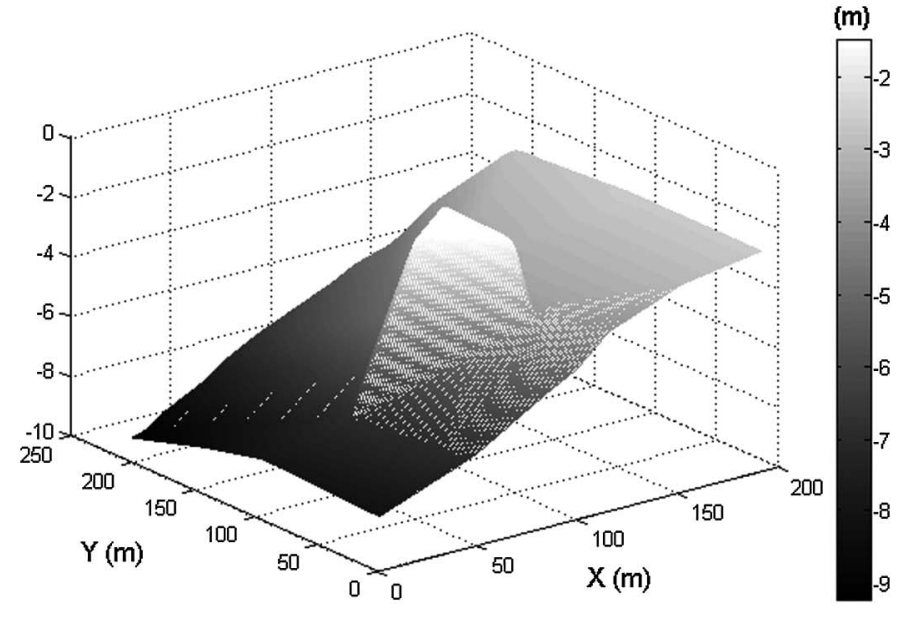

(a)

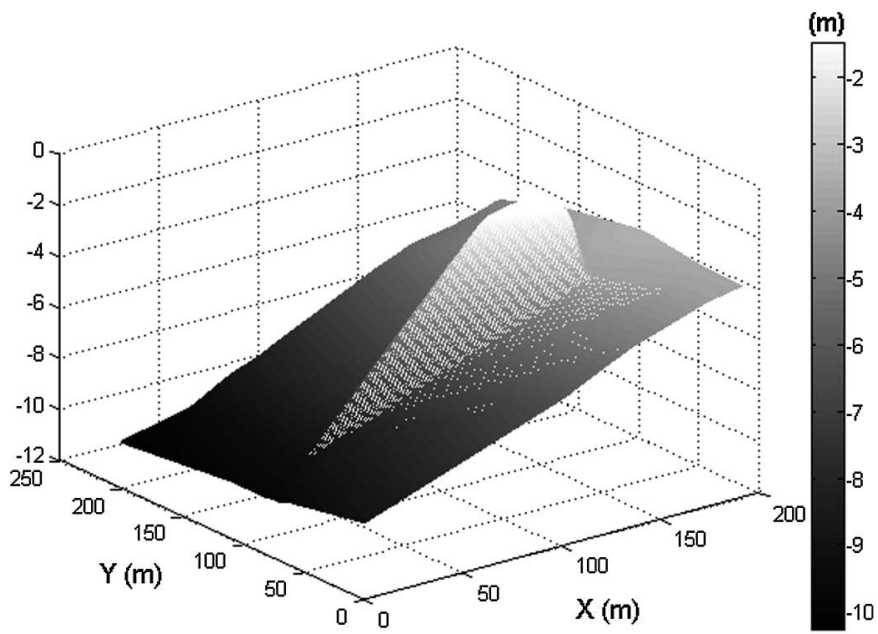

(b)

Fig. 6. Local bathymetry of Leirosa's coastal area: (a) reef geometry detail with a $45^{\circ}$ angle; (b) reef geometry detail with a $66^{\circ}$ angle

Table 2. Wave Conditions Tested in Numerical Model, Length of Ride for Multifunctional Artificial Reef, Iribarren Number, and Peel Angle along Breaking Lines

\begin{tabular}{|c|c|c|c|c|c|c|c|}
\hline Case & $H(\mathrm{~m})$ & $T(\mathrm{~s})$ & $\begin{array}{c}\text { Reef } \\
\text { angle }\left({ }^{\circ}\right)\end{array}$ & $\begin{array}{l}\text { Length of left } \\
\text { ride }(\mathrm{m})\end{array}$ & $\begin{array}{l}\text { Length of right } \\
\text { ride }(\mathrm{m})\end{array}$ & $\begin{array}{c}\text { Iribarren } \\
\text { number }\end{array}$ & $\begin{array}{c}\text { Peel } \\
\text { angle }\left({ }^{\circ}\right)\end{array}$ \\
\hline $\mathrm{C} 0$, mean tide water level & 1.5 & 8.0 & - & - & - & - & - \\
\hline $\mathrm{C} 1$, mean tide water level & 4.0 & 15.0 & 45 & - & - & 一 & - \\
\hline $\mathrm{C} 2$, mean tide water level & 4.0 & 15.0 & 66 & - & - & - & - \\
\hline $\mathrm{C} 3$, mean tide water level & 1.5 & 9.0 & 45 & $\approx 300$ & $\approx 300$ & $0.76-0.96$ & $27-65$ \\
\hline $\mathrm{C} 4$, mean tide water level & 1.5 & 9.0 & 66 & $\approx 150$ & $\approx 120$ & $0.70-1.09$ & $50-65$ \\
\hline C5, low tide water level & 1.5 & 9.0 & 45 & $\approx 150$ & $\approx 150$ & $0.79-0.94$ & $25-43$ \\
\hline C6, low tide water level & 1.5 & 9.0 & 66 & $\approx 80$ & $\approx 80$ & $0.73-1.05$ & $47-61$ \\
\hline
\end{tabular}



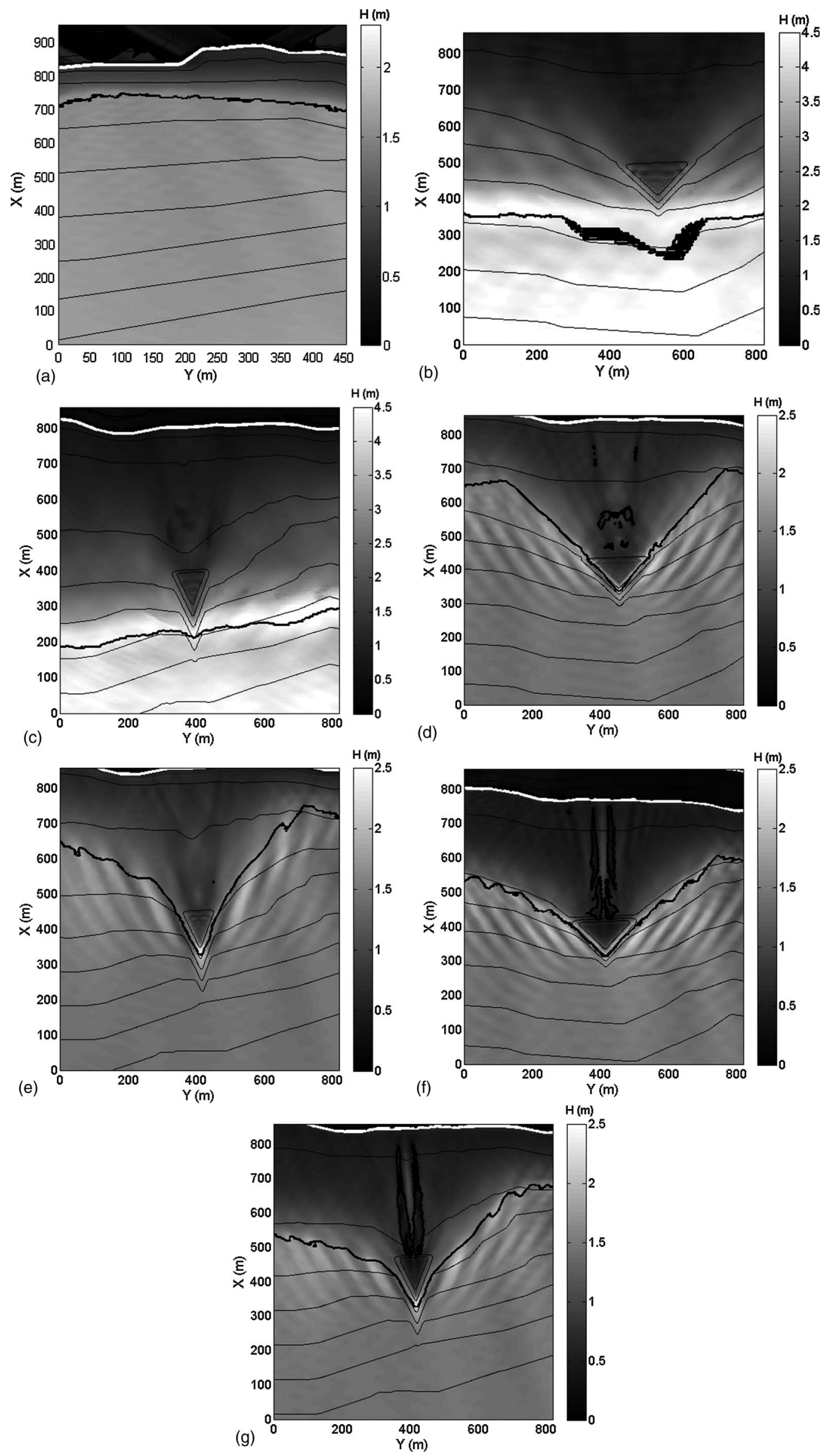

Fig. 7. Wave heights and wave breaking lines (black bold lines) around reef area: (a) $\mathrm{C} 0$; (b) $\mathrm{C} 1$; (c) $\mathrm{C} 2$; (d) $\mathrm{C} 3$; (e) $\mathrm{C} 4$; (f) $\mathrm{C} 5$; (g) $\mathrm{C} 6$ 
wave conditions and reef geometries tested and reproduced in the present study, the breaker type is in accordance with the categorization proposed by Battjes (1974) for a plane beach.

\section{COULWAVE Numerical Model}

COULWAVE (Lynett and Liu 2004) is a nonlinear wave propagation model that uses a multilayer approach for the integration of the primitive equations of motion (continuity and momentum equations).

Included in the numerical code is a parameterization of bottom friction and wave breaking, in addition to a moving boundary scheme to simulate wave runup and rundown (Kennedy et al. 2000).

This study considers one layer only, often referred to as the "fully nonlinear, extended Boussinesq equations" in the literature (Wei and Kirby 1995; Wei et al. 1995), which has been examined and applied to a significant extent. The equations are solved using a high-order predictor-corrector scheme, a third-order in-time explicit Adams-Bashforth predictor step, and a fourth-order in-time Adams-Moulton implicit corrector step (Press et al. 1989).
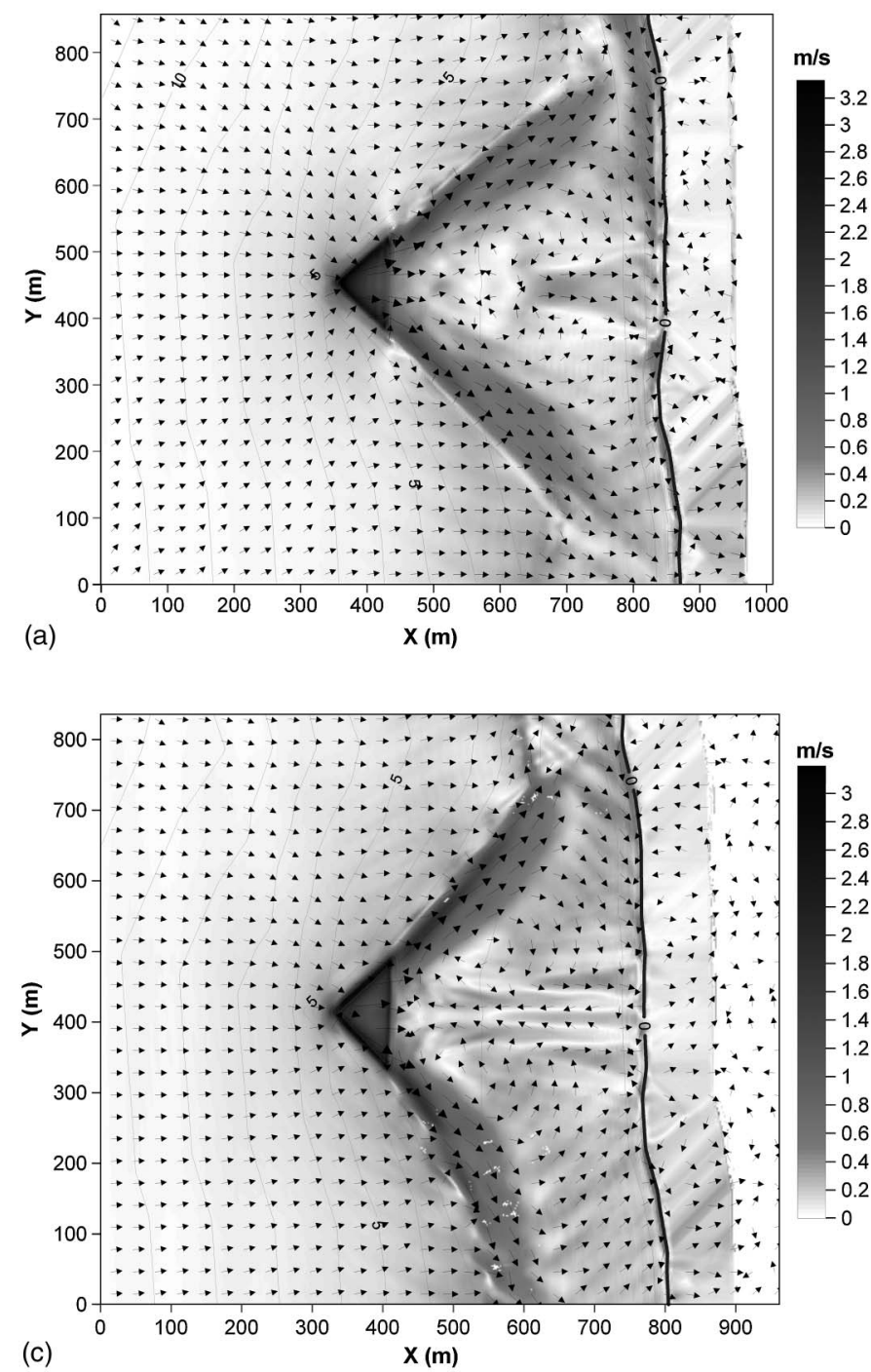

The study area, the local wave conditions, and the primary conditions for the application of the COULWAVE model are described next.

\section{Reef Performance Analysis}

\section{Surfability}

The COULWAVE numerical model was applied for the wave conditions shown in Table 2. A triangular reef geometry was tested by varying the reef angle $\left(45\right.$ and $66^{\circ}$ ). A case without a reef (case $\mathrm{C} 0$ ) was also analyzed. The results of the wave heights and the breaking line for each condition are shown in Fig. 7, and the variation of the Iribarren number is shown in Table 2.

Along the reef, an increase of the wave height is observed, in opposition to the situation without the reef, owing to the decrease of the depth in the reef zone. Moreover, owing to the increase in wave heights, the wave breaking occurs earlier (and in general over the reef) in comparison with the situation without a reef. From Fig. 7, it is clear that the presence of the reef significantly alters the wave heights, with the wave height increasing along the reef as a consequence of decreasing water depth.
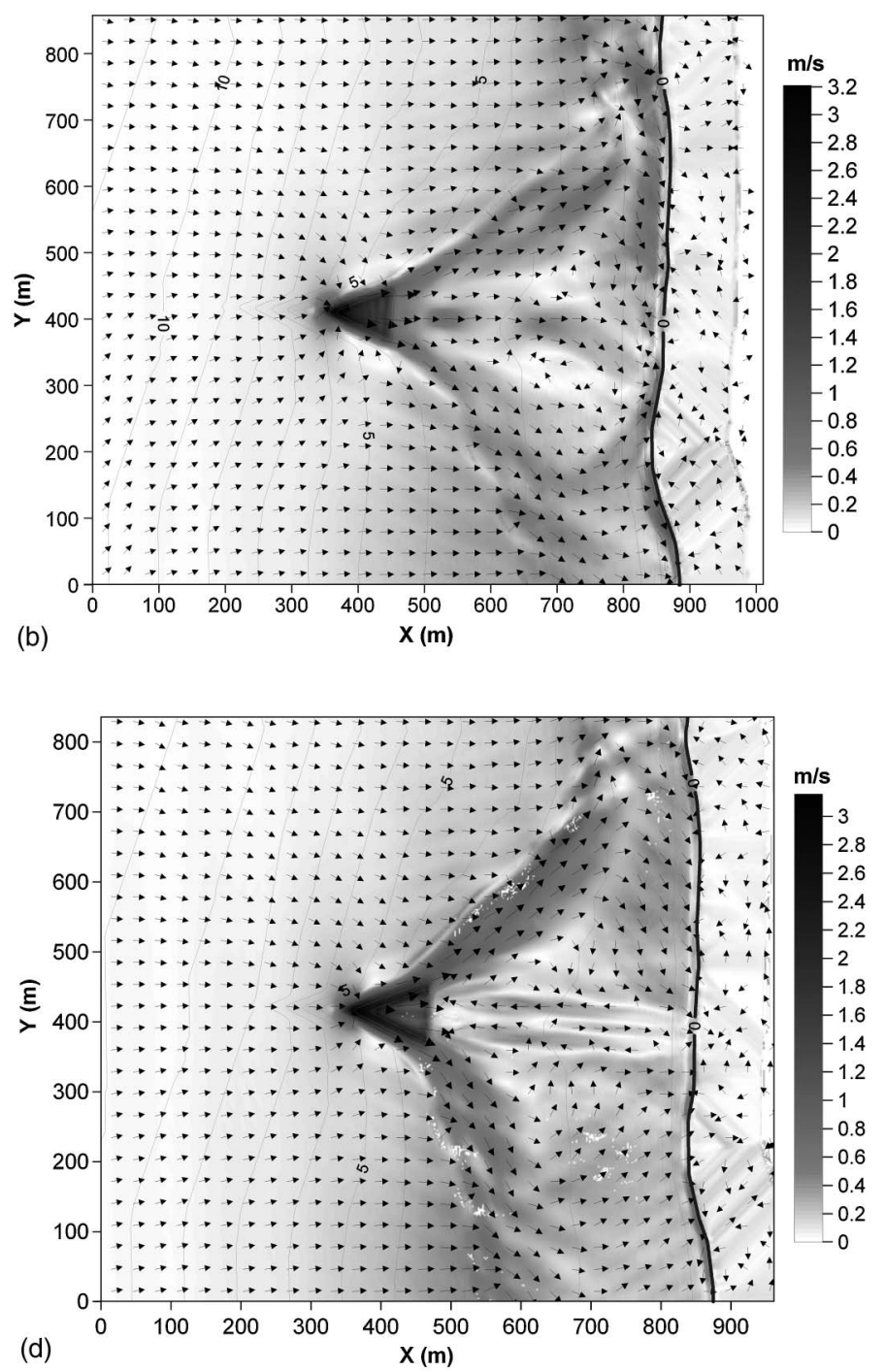

Fig. 8. Mean currents (a) C3; (b) C4; (c) C5; (d) C6 
For the cases representative of storm condition (C1 and $\mathrm{C} 2)$, the wave is breaking near the apex of the structure, parallel to the coast, with wave heights of approximately $4.5 \mathrm{~m}$. These conditions are unfavorable for surfing, so they will not be explored in the subsequent sections. In the cases representative of common conditions (C3-C6), the artificial reef causes the wave height to increase, especially at the apex of the structure, and causes a breaking line that follows its geometry.

The variation of the Iribarren number along the breaker line is shown in Table 2, in which the minimum value corresponds to the apex of the structure.

For the simulated cases of the surfing conditions, the Iribarren number varies from $0.7-1.1$, corresponding to a plunging breaking wave. This range of the Iribarren number is in agreement with Van Ettinger's (2005) findings, which stipulate that an Iribarren number ranging between $0.7-0.9$ is expected to result in a nice plunger suitable for surfing. A common tendency is observed: from the apex of the structure and toward the shoreline, following the breaker line, the Iribarren number increases. To catch the wave at the start, a smaller wave value of approximately 0.6 at the beginning of the ride is preferred. The values at the apex correspond to the beginning of the ride, ranging from 0.7 to approximately 0.8 .

The peel angle along the breaker line is related to the velocity that a surfer can reach and the surfer's skill and is expected to start at approximately $30^{\circ}$ for professional surfers, reaching approximately $60^{\circ}$ for standard surfers. For this, the wave direction along the breaker line should be known.

COULWAVE outputs include the free surface elevation in time and in space and the horizontal velocity components $u$ and $v$, which represent the local flow direction. The wave direction is not a direct output.

The mean wave direction $\theta(f)$ was calculated in this study using the methodology of Longuet-Higgins et al. (1963). Thus, arrays of the free surface elevation $\eta$ and of the horizontal velocities components $u, v$ time series were considered, and a directional spectral analysis was performed, similar to what may be done in a laboratory flume to determine the wave direction from a set of wave gauges.

An algorithm was developed in a matrix laboratory (MATLAB) to organize the information related to $\eta, u$, and $v$ for several points of the computational grid, and the direction was obtained using the directional wave spectra (DIWASP) software developed at MetOcean Solutions Ltd. (New Plymouth, New Zealand) (Johnson 2000). The direct Fourier transform estimation method was used to build the directional spectra (Barber 1961). On the basis of these calculations, the peel angle was determined, as shown in Table 2.

For cases C3-C6, representative of common conditions, the peel angle values indicate that the geometry with a reef angle of $66^{\circ}$ would be more suitable for standard surfers, whereas the geometry with a reef angle of $45^{\circ}$ would be more suitable for advanced/professional surfers.

The length of the ride induced by the MFAR is calculated observing the Iribarren number and the peel angle along the breaker line, with the peel angle being the more limiting parameter. Table 2 shows the length of the ride for cases C3-C6 for each side of the MFAR, starting at the apex of the structure and toward the shoreline, following the breaker line.

The length of the ride is longer for a reef angle of $45^{\circ}$ (cases $\mathrm{C} 3$ and $\mathrm{C} 5$ ).

Concerning the wave height at the breaker point, the preferred wave height depends on the skill of the surfer. The greater the skill of the surfer, the higher the wave preferred. However, for any surfer, it is easier to start surfing when the wave is somewhat higher at the beginning, especially when the peel angle is small.
The peel angle variability along the breaker line indicates the existence of various wave sections in which different types of maneuvers can be performed (Scarfe 2002; Scarfe et al. 2002), challenging surfers and keeping rides interesting. For instance, in case $\mathrm{C} 3$, the left ride shows the possibility of surfing through a speed section $\left(35^{\circ}<\alpha<45^{\circ}\right)$ in which the surfer can speed weave, perform a cutback $\left(53^{\circ}<\alpha<62^{\circ}\right)$, or experience a barrel ride if the breaker intensity is great enough.

\section{Currents}

The mean currents around the reef were analyzed, and the output of the model corresponds to the velocity at a depth $0.531 \mathrm{~h}$ below the water surface, where $h$ is the water depth. The velocity at this depth is taken by several authors (Nwogu 1993) as the characteristic depth of the flow and was adopted by the authors of the COULWAVE model (Lynett and Liu 2004). Because this work is just a preliminary analysis of the flow, intended to give an indication of currents generated by the reef, the output velocity at a depth $0.531 h$ below the water surface is used to determine the velocity cells near the surf reef (Fig. 8).

The mean currents for cases C3 and C4 are approximately in favor of the wave direction, contributing to a smooth water surface and stable wave breaking. Conversely, for cases C5 and C6, currents are against the wave direction, affecting the breaking significantly by making waves steeper and breaking in an unstable way.

\section{Conclusions}

This paper presented a preliminary study of the functionality of an (MFAR), to be implemented in Leirosa, Figueira da Foz, Portugal.

On the basis of the analysis of the local wave regime and on the geometry proposed by Voorde et al. (2009), a Boussinesq-type model (COULWAVE) was applied to study the wave propagation over the MFAR.

The simulated cases correspond to storm conditions ( $H=4.0 \mathrm{~m}, T=15 \mathrm{~s})$, representing the design conditions for coastal protection, and to local common conditions $(H=1.5 \mathrm{~m}$, $T=9 \mathrm{~s}$ ), representing the design conditions for surfing, considering two triangular reef geometries with reef angles of 45 and $66^{\circ}$.

The reef performance was analyzed for the so-called surfability. An indication related to coastal protection has been presented on the basis of the mean wave currents induced by the reef.

With respect to surfability, both geometries suggest long breaker lines that are suitable for surfing, with wave heights of approximately $2.5 \mathrm{~m}$ at the apex of the structure, for an incident wave of $1.5 \mathrm{~m}$. The analysis of the Iribarren number indicates a plunging breaking wave with values between $0.7-1.1$ for all cases. The peel angle values indicate that the geometry with a reef angle of $66^{\circ}$ would be better suited to standard surfers, whereas the geometry with a reef angle of $45^{\circ}$ would be more suitable for advanced/professional surfers.

In the analysis for coastal protection, the mean currents around the reef were used, and through the observation of the velocity cells near the shoreline, preliminary indications on the sediment transport were obtained. For all cases, convergent cells seem to indicate a possible sedimentation near the shoreline. Nevertheless, a morphodynamic study needs to be performed to provide a deeper insight into the modes of erosion and/or sedimentation in the area.

\section{Acknowledgments}

This project has been supported by the Fundação para a Ciência e a Tecnologia through grants PTDC/ECM/66516/2006 and PTDC/ ECM/67411/2006. 


\section{References}

Antunes do Carmo, J. S., Schreck Reis, C., and Freitas, H. (2010). "Working with nature by protecting sand dunes: Lessons learned." J. Coastal Res., 26(6), 1068-1078, 10.2112/JCOASTRES-D-10-00022.1.

Barber, N. F. (1961). "The directional resolving power of an array of wave detectors." Ocean wave spectra, Prentice Hall, Upper Saddle River, NJ, 137-150.

Battjes, J. A. (1974). "Surf similarity." Proc., 14th Int. Conf. on Coastal Engineering, ASCE, Reston, VA, 466-479.

Beamsley, B., and Black, K. (2003). "The effect of offshore reefs on inshore surfing conditions." Proc., 3rd Int. Surfing Reef Symp., Raglan, New Zealand, 99-114.

Bowen, A. J. (1969). "Rip currents. 1: Theoretical investigations." J. Geophys. Res., 74(23), 5467-5478.

Cáceres, I., Trung, Le H., van Ettinger, H. D., Reniers, A., and Uijttewaal, W. (2010). "Wave and flow response to an artificial surf reef: Laboratory measurements." J. Hydraul. Eng., 136(5), 299-310.

Costa, M. (2009). "Tratamento de dados de agitação marítima: Leirosa." Instituto Hidrográfico, Oceanography Division, Lisbon, Portugal (in Portuguese).

Dally, W. R. (2001). "The maximum speed of surfers." J. Coastal Res., SI (29), 33-40.

Duarte, D. N., and Reis, R. P. (1992). "Estudo preliminar da evolução da linha de costa adjacente à embocadura do estuário do Mondego entre 1801 e 1989: Estimações das taxas de acreção e erosão costeiras." Actas do III Congr. Geol. España y VIII Congr. Latimoamericano de Geologia, 2, Universidad de Salamanca, Salamanca, Spain, 146-150 (in Portuguese).

European Commission. (2004). "Living with coastal erosion in Europe: Sediment and space for sustainability." Eurosion study Eurostat, Luxembourg.

Galvin, C. J., Jr. (1968). "Breaker-type classification on three laboratory beaches." J. Geophys. Res., 73(12), 3651-3659.

Gomes, F. V., and Pinto, F. T. (2006). Eurosion case study Vagueira-Mira (Portugal), Instituto de Hidráulica e Recursos Hídricos, Porto, Portugal.

Hearin, J. M. (2006). "Preliminary design of an artificial surfing reef for Cocoa beach, Florida." M.Sc. thesis, Florida Institute of Technology, Melbourne, FL.

Henriquez, M. (2004). "Artificial surf reefs.” M.Sc. thesis, Delft Univ. of Technology, Delft, The Netherlands.

Henriquez, M., Janssen, T. T., Van Ettinger, H. D., and Reniers, A. J. H. M. (2006). "Refraction-controlled surfability." Proc., 5th Int. Artificial Surfing Reef Symp., Lombok Indonesia.

Hiliau, W., and Phillips, D. (2003). "Artificial surfing reef construction." Proc., 3rd Int. Surfing Reef Symp., Raglan, New Zealand, 378-397.

Hutt, J. A., Black, K. P., and Mead, S. T. (2001). "Classification of surf breaks in relation to surfing skill." J. Coastal Res., SI(29), 66-81.

Jackson, L. A., Reichelt, R. E., Restall, S., Corbett, B., Tomlinson, R., and McGrath, J. (2004). "Marine ecosystem enhancement on a geotextile coastal protection reef-Narrowneck reef case study." Proc., 29th Int. Conf. on Coastal Engineering, National Civil Engineering Laboratory, Lisbon, Portugal, 3940-3952.

Johnson, D. (2000). "DIWASP, a directional wave spectra toolbox for MATLAB ®: User manual.” Research Rep. WP-1601-DJ (V1.1), Centre for Water Research, Univ. of Western Australia, Crawley, Australia.

Kennedy, A. B., Chen, Q., Kirby, J. T., and Dalrymple, R. A. (2000). "Boussinesq modeling of wave transformation, breaking, and runup. Part I: 1D." J. Waterway, Port, Coastal, Ocean Eng., 126(1), 39-47.

Longuet-Higgins, M. S., Cartwright, D. E., and Smith, N. D. (1963). "Observation of the directional spectrum of SRA waves using the motions of a floating buoy." Ocean wave spectra, Prentice-Hall, Upper Saddle River, NJ.

Lynett, P., and Liu, P. L.-F. (2004). "Modeling wave generation, evolution, and interaction with depth integrated, dispersive wave equations." Coulwave Code Manual, Cornell Univ. Long and Intermediate Wave
Modeling Package, Cornell University, Ithaca, NY, 179 〈http:// ceeserver.cee.cornell.edu/pll-group/doc/COULWAVE_manual.pdf $\rangle$.

MacMahan, J. H., Thornton, E. B., and Reniers, A. J. H. M. (2006). "Rip current review." Coastal Eng., 53(2), 191-208.

Moores, A. (2001). "Using video images to quantify wave sections and surfers parameters." M.Sc. thesis, Univ. of Waikato, Hamilton, New Zealand.

Neves, M. G., Mendonça, A., Borrego, M., and Antunes do Carmo, J. S. (2010). "Bidimensional wave breaking tests over a submerged reef built with geotextile sand containers." Proc., 3rd Int. Conf. on the Application of Physical Modelling to Port and Coastal Protection (COAST$\left.L A B^{\prime} 10\right)$, Barcelona, Spain, in press.

Nwogu, O. (1993). "Alternative form of Boussinesq equations for nearshore wave propagation." J. Waterway, Port, Coastal, Ocean Eng., 119(6), 618-638.

Phillips, D. J., Mead, S. T., Black, K. P., and Healy, T. R. (2003). "Surf zone currents and influence on surfability." Proc., 3rd Int. Artificial Surfing Reef Symp. (CD-ROM), Univ. of Waikato, Hamilton, New Zealand.

Pilarczyk, K. W. (2003). "Design of low-crested (submerged) structures: An overview." Proc., 6th Int. Conf. on Coastal and Port Engineering in Developing Countries (COPEDEC VI), R. Galappatti, ed., Lanka Hydraulic Institute, Moratuwa, 1-18.

Press, W. H., Flannery, B. P., and Teukolsky, S. A. (1989). Numerical recipes, Cambridge University Press, Cambridge, U.K.

Ranasinghe, R., Turner, I. L., and Symonds, G. (2006). "Shoreline response to multi-functional artificial surfing reefs: A numerical and physical modelling study." Coastal Eng., 53(7), 589-611.

Scarfe, B. E. (2002). "Categorising surfing manoeuvres using wave and reef characteristics." Master's thesis, Univ. of Waikato, Hamilton, New Zealand.

Scarfe, B. E., de Lange, W. P., Chong, A. K., Black, K. P., and Mead, S. T. (2002). "The influence of surfing wave parameters on maneuver type from field investigations at Raglan, New Zealand." Proc. for the 2nd Surfing Arts, Science and Issues Conf. (SASIC 2), The Groundswell Society, 74-89.

Scarfe, B. E., Elwany, M. H. S., Mead, S., and Black, K. P. (2003). "The science of surfing waves and surfing breaks: A review." Proc., 3rd Int. Surfing Reef Symp., Scripps Institution of Oceanography, Univ. of California San Diego, San Diego.

Shepard, F. P., and Inman, D. L. (1950). "Nearshore water circulation related to bottom topography and wave refraction." Trans., Am. Geophys. Union, 31(2), 196-212.

Van Ettinger, E. (2005). "Artificial surf reef design.” M.Sc. thesis, Faculty of Civil Engineering and Geosciences, Delft Univ. of Technology, Delft, The Netherlands.

Voorde, M. T. (2009). "Contributions to the design of multi-functional artificial reefs." Ph.D. thesis, Dept. of Civil Engineering, Faculty of Sciences and Technology of the Univ. of Coimbra, Coimbra, Portugal.

Voorde, M. T., Antunes do Carmo, J. S., and Neves, M. G. (2009). "Multifunctional artificial reefs for coastal protection." Chapter 7, Agricultural runoff, coastal engineering and flooding, Ch. A. Hudspeth, and T. E. Reeve, eds., Nova Science Publishers, Hauppauge, NY, 153-210.

Voorde, M. T., Neves, M. G., and Antunes do Carmo, J. S. (2008). "Preliminary study on the geometry of an artificial reef for coastal protection and surfing along the West coast of Portugal." J. Integ. Coastal Zone Manage., 8(1), 65-79 (in Portuguese).

Walker, J. R. (1974). "Recreational surf parameters." Technical Rep. 30, James K. K. Look Laboratory of Oceanographic Engineering, University of Hawaii, Manoa, HI.

Wei, G., and Kirby, J. T. (1995). "A time-dependent numerical code for extended Boussinesq equations." J. Waterway, Port, Coastal, Ocean Eng., 121, 251-261.

Wei, G., Kirby, J. T., Grilli, S. T., and Subramanya, R. (1995). "A fully nonlinear Boussinesq model for surface waves. I: Highly nonlinear, unsteady waves." J. Fluid Mech., 294, 71-92. 